\title{
The Effectiveness of Using Brainstorming Strategy in the Development of Academic Achievement of Sixth Grade Students in English Grammar at Public Schools in Jordan
}

\author{
Nibal Abdelkarim Mousa Malkawi ${ }^{1} \&$ Mona Smadi $^{2}$ \\ ${ }^{1}$ Al Balqa Applied University, Salt, Jordan \\ ${ }^{2}$ Princess Alia University College, Al Balqa Applied University, Amman, Jordan \\ Correspondence: Nibal Abdelkarim Mousa Malkawi, Al Balqa Applied University, Salt, Jordan. E-mail: \\ nibal_malkawi@yahoo.com
}

Received: October 2, 2017

Accepted: November 20, 2017

Online Published: February 25, 2018

doi: $10.5539 /$ ies.v $11 \mathrm{n} 3 \mathrm{p} 92$

URL: https://doi.org/10.5539/ies.v11n3p92

\begin{abstract}
The study aims to identify the effect of using brainstorming method in the teaching of English grammar; to improve the level of sixth grade students in English grammar at public schools in Jordan. The study population consisted of all sixth grade students of both sexes. The sample of the study was chosen in the random stratified manner, represented in four schools: two for males and two for females, which were divided into two groups (experimental and control). The results showed that there were significant differences at the level of $(\alpha=0.05)$ in the achievement test in the English grammar, in favor of the experimental group. The results also showed significant differences between males and females in the achievement test in favor of the females. One of the most prominent recommendations was to refer to those concerned with educational guidance, and school administrations to give priority to the issue of the weakness of students in English grammar by focusing on the use of modern methods of teaching, including the method of brainstorming.

This study deals with a vital subject concerns those interested in the educational process, especially in the field of teaching English, where the study sheds light on the method of brainstorming and how to benefit from it to narrow the gap resulting from traditional practices in the teaching of English grammar, in order to reach objective results that reflect the pedagogical and educational reality regarding the level of students' achievement in the English grammar.
\end{abstract}

Keywords: brainstorming, academic achievement development, creative thinking, traditional method of teaching

\section{Introduction}

The current era is characterized by rapid changes surrounded by many challenges. These changes included scientific progress, technological development and openness to the world of communication. In order to cope with these rapid developments we have to pay attention to the development of creative minds capable of solving existing problems. The development of students' mental abilities has become the main goal of the educational process in all countries of the world, as the progress of countries is measured by in the capacity to develop the minds of their children.

To achieve this, many countries have made strenuous efforts, spent huge sums of money, and carried out more research, in accordance with the principles of objective education that seek to organize students' thinking and utilize their creative potential and investment (Tabtay, 2001).

In this context, it is necessary to provide an environment in which students are personally involved "in the process of building and learning the effective learning environment, which aims at helping the student to gather ideas and give the appropriate decisions to reach the correct conclusions.

The choice of effective instructional methods is not only to improve the level of achievement of students in the preparation period, but also to become part of the "preparation program and to be helpful" in the future practice of education.

This method of teaching "based on the interaction between the teacher and the learner or between the learner and other learner, as this helps in the development of thinking methods or reduce the methods of automation that are 
given in one direction from the teacher to the learner" (Husari et al., 2000).

Fontaine (1981) stressed that brainstorming is a way of bringing ideas without consideration of their evaluation. This does not mean leaving the evaluation, but only postponing it to the end of the session. The brainstormer should be aware that brainstorming is not guaranteed to get new ideas. "Brainstorming is not just a way to encourage new ideas, but to encourage all participants to contribute to teamwork (Wahib \& Zidane, 2001).

Brainstorming is important for male and female teachers, it allows tracking and flow of ideas, and follow the ways of running the idea or ideas in the minds of students, and gives them an idea about trends that children go to them when they deal with a problem or an unspecified situation, or without controls, and helps them to know the levels of mental stock, and methods of processing students for ideas that have not prepared or not known for them, which are known as "mental moments" and often required attitudes facing them in normal life (Katami et al., 2008)

Brainstorming is one of the most distinctive ways to develop creative thinking, so the nature of the brainstorming is characterized as working on the flow of ideas without criticism and try to speed thinking, break the deadlock, and challenge the minds. (Hassanein 2002), focuses on the positive participation of learners in the educational process, and invites them to build different patterns and images of ideas, to expand their creative views, and open their minds, during addressing problems, proposing solutions, and presenting terminology, on the contradictions existing in problem, and then the learners can collect scientific knowledge of the facts and concepts and scientific principles, laws and theories, and the collection of cognitive aspects necessary to understand phenomena, events and adaptation with it (Abdelkader, 1997)

\subsection{Problem of the Study}

Despite the continuous efforts exerted by the Ministry of Education in Jordan, represented by all its educational institutions, aimed at improving the quality of the learning process, there is still a gap between the negative results in terms of the level of achievement in English language skills and its grammar did not reach the required level.

Within the framework of the search for finding a way to overcome this phenomenon, the study seeks to research the strategy of teaching related to the life of students, the use of the method of brainstorming in the teaching of grammar for the sixth grade in public schools in Jordan, and testing it and studying its impact on academic achievement, the researcher hopes that the results of this study and its recommendations will contribute to improving the methods of using modern teaching methods in teaching English in general, teaching English language skills and grammar in particular, and stimulating and encouraging students to study these rules and assimilation and then employing it.

\subsection{Questions of the Study}

To achieve the objectives of the study, the researcher tries to answer the following questions:

1) What is the effect of the use of brainstorming method in the achievement of the sixth grade students in the basic skills of English grammar compared to the traditional (regular) methods of teaching?

2) Are there statistically significant differences in the extent of the brainstorming method effectiveness on students' achievement in the experimental group of English grammar skills at the level of $(\alpha=0.05)$ due to the gender of students (males or females)?

\subsection{The Importance of the Study}

This study is important because it addresses a vital topic that concerns many, and the parties involved in the process of learning and teaching, in order to raise the achievement level of students in the rule of English language, while we see a clear weakness in students to acquire skills and apply the rules correctly In their writings and in their talk, and this study came to highlight the method of brainstorming and how to use it to bridge the gap resulting from traditional practices in the teaching of English grammar, and benefit from the results to improve the level of achievement of students in this subject.

\subsection{Objectives of the Study}

The study aims to achieve the following main objectives:

- Investigating the impact of the use of brainstorming strategies on teaching, and its effectiveness in students' achievement of English language skills and grammar through the development of good thinking, stimulating students and encouraging them to acquire these skills.

- Exploring the impact of using brainstorming method compared to traditional methods of teaching to develop the achievement of sixth grade students in Jordan and encouraging them to learn the skills related to English grammar. 
- To reach objective results that reflect the educational reality regarding the level of students' achievement in the English grammar, and to develop recommendations that can contribute to the development of teaching methods in this field.

\subsection{The Limits of the Study}

The study was limited to the application of the method of brainstorming and the traditional method of teaching on the subjects of language applications; (English grammar) of the English language book, part one, for the sixth grade. And it was applied in the second semester of the academic year 2016 - 2017.

\section{Previous Studies}

May studies were conducted to investigate the effectiveness of using brain storming method on the students' achievement; the researcher reviewed some of these studies as follows:

Jack and Kyado (2017) conducted a study entitled 'Effectiveness of Brain-based Learning Strategy on Students' Academic Achievement, Attitude, Motivation and Knowledge Retention in Electrochemistry" this study aimed at investigating the effect of Brain-Based Learning strategy on students' academic achievement, motivation, attitude and knowledge retention in Electrochemistry. The researcher used a pretest-posttest quasi-experimental design. The sample of the study consisted of (87) Senior Secondary students from North-Eastern part of Nigeria in 2015/2016. The sample of the study was divided into two groups, experimental and control. The experimental group was taught using Brain-Based Learning (40) the control group were taught using the traditional way (47). The researchers used achievement test, and attitude and motivation scales to collect the data, and then they analyzed it statistically using means, and independent t-test, and Analysis of Covariate which were used to compare the groups' scores. The results of the study showed that the Brain-Based Learning strategy was more effective in increasing students' achievement, attitude and motivation of students towards chemistry than the traditional way used in the control group. The results also showed that the difference between retention test scores were also statistically significant in favor of experimental group.

Wisdom, Victoria, and Emmanuel (2016) conducted a study its aim to examine the effect of brainstorming strategy on students' prior knowledge and academic performance in chemistry. The sample of the study consisted of (148) participants ( 77 males and 71 females) they were selected purposefully from four coeducational secondary schools in two states in Nigeria. They were divided into two groups: experimental (73) students and control (75) students groups- the experimental group was taught using brainstorming strategy while the control was taught using the traditional way of teaching. The researchers used Pre/posttest, mean and analysis of covariance (ANCOVA) were used to analyze the data. The results of the study showed that there are statistically significant difference in both means of knowledge and academic performance in favor of the experimental group. The results also showed that there is no statistically significant difference in the mean of academic performance of students in the experimental group. Furthermore, the study showed there is no significant interaction effect of brainstorming strategy and gender on academic performance. The researchers recommended that appropriate instructional strategies and packages that can induce students' previous knowledge to stimulate learning should be used by teachers and science curriculum designers.

Hashempour, Rostampour, and Behjat (2015) conducted a study its aim is to investigate the effectiveness of using brainstorming and its subcategories strategy (question and answer, listing, outlining) as a pre-writing strategy. The sample of the study consisted of (60) Iranian EFL advanced students from both sexes. The researchers used a questionnaire to measure the attitude of students toward the instruction strategy. The results of the study showed that there was no significant relationship between EFL learners writing development and brainstorming, and its subcategories. Moreover, the results also showed that there was no significant difference between students in using brainstorming and its subcategories due to gender.

Salamat and Kharashah (2010) conducted a study its aim was to know the effectiveness of brainstorming on the seventh grade students' achievement in geography and the development of trends towards it. The researchers used the experimental approach, the sample consisted of (45) students from the seventh grade, who were distributed randomly into two groups, i.e., experimental group and other control, the tools used were achievement test and measure of trends towards geography. Through the use of researchers, the study reached the results, (ANCOVA) Statistical Methods, such as the analysis of common variation between the following arithmetic averages:

the existence of statistically significant differences at $(\alpha=0.05)$ for the grades of the students of the experimental and control groups on the achievement test, and the scale of trends towards geography are attributed to the teaching method, and to the students of the experimental group, which studied using the brainstorming method, and the study recommended using the method of brain storming in teaching social education materials and training teachers to use the brainstorming method. 
The study of Ziadat and Adwan (2009) aimed to know the effect of brainstorming on the development of decision-making skills of the ninth grade students in the field of national education and civic education in Jordan.The researchers used the experimental method, and the sample of the study consisted of a random sample that included (158) students who were divided into two experimental groups, experimental group consisting of (81) students, and control group (77) students. The study tools were a scale that measured decision-making skill, and plans to develop lessons in brainstorming, and through the use of the following statistical methods: arithmetical averages, standard deviations, $\mathrm{T}$ test, and the analysis of the binary variance, the study reached the following results: There are significant differences in the development of decision-making skills in favor of brainstorming method, and the absence of statistical significant differences in the development of decision-making skills are attributed to gender, and there are no differences due to interaction between method and gender. The study recommended using the method of brainstorming in teaching different materials, and training teachers to use brainstorming method.

Agha (2009) study aimed at finding out the effect of using brainstorming strategy in developing mathematical thinking skills on both sides of the brain in the eleventh grade students of the scientific branch, and the researcher used experimental approach. The study sample consisted of two groups, experimental group (30) students, and control group (30) students of the eleventh grade from the scientific branch, and the sample was chosen purposefully, and the parity between the two groups was considered in terms of chronological age and previous achievement in mathematics. The study tools were: Brain control test, and a test of the researcher's design relates to some mathematical thinking skills (Induction, inquiry, conclusion, rationalism, problem solving, symbolization). And through the researcher's use of statistical methods, which are repetitions and arithmetic averages for two independent samples, test (man- witty) for the two samples t-test (and percentage, test (Crosack-Wilson) test for three independent samples, the researcher found the following results: The existence of differences between the experimental and control groups in favor of the experimental group, which emphasizes the positive use of brainstorming strategy on the development of mathematical thinking in the side of brain in the eleventh students of the scientific branch, and the study recommended using the brain storming strategy in the teaching of mathematics, and attention to the development of the mental abilities of learners.

The study of the Shulah (2009) which aimed to know the effect of brainstorming in the teaching of Educational psychology on both the curiosity and performance improvement on psychology tests with higher mental levels in Saudi Arabia, and the researcher used the experimental method, the descriptive approach, and the sample of the study consisted of (30) students from the faculty of teachers, and were divided into two groups, experimental group (15) students, and the control group (15) students, the tools which were used: achievement tests and the scale of curiosity. The researcher used the following statistical methods: Standard deviations, arithmetic averages, (t) test, correlation coefficient, and the study reached the following results: The effectiveness of brainstorming in the teaching of educational psychology course, and the impact on the development of curiosity and improve the level of performance on the achievement tests prepared in the light of higher mental levels, the study recommended the use of a brainstorming strategy in the teaching of curriculum courses in teacher preparation colleges, and interest the programs for developing the capacity of university teaching staff and train them to use Brainstorming in teaching.

Abu Sneineh (2008) Study aimed at revealing the effect of using brainstorming method in the development of achievement and critical thinking in geography among the students of the educational science college UNRWA, and the researcher used the experimental approach, the sample was composed of all the students of the teacher's specialization in the third year (131) students divided into five divisions, and then two divisions were selected randomly, one of which was allocated as a experimental group, consisted of (25) students who were taught through using brainstorming method, and the other was control group consisted of (28) students were taught in the traditional way, and then the achievement test prepared by the researcher was used and test for critical thinking, and through the researcher use of the following statistical methods: means, standard deviations, and T- test. The study reached the following results: There are differences of statistical significance at the level of significance $(\alpha=0.05)$ in favor of the experimental which was taught using brain storming strategy, no statistically significant differences in the skills of inference and conclusion. The study recommended that university faculty members have to employ the brainstorming method in the teaching of different courses, especially the geography course on the level of universities and schools.

\section{Method and Procedures}

This section describes the method and procedures used by the researcher in this study, which illustrate the study population, its sample, design, tools and procedures, statistical processing used in data analysis, and discussion of results. 


\subsection{Population of the Study}

The study population consists of all sixth grade students enrolled in public schools in the Wadi Al-Seer directorate of education/Jordan in the second semester of the academic year 2016-2017. The number of students is (1634), (732) males and (902) females.

\subsection{The Study Sample}

The sample of the study was chosen in the random stratified form. It consisted of four sections of the sixth grade students from four public schools belonging to Wadi Al-Seer directorate of education, including two male schools and two other female schools, which were divided into two groups:

- The experimental group; it included a male and a female school.

- The control group; it also included a male and a female school.

\subsection{Study Approach}

In order to achieve the objectives of the research, and based on its hypotheses, this study required the descriptive approach to research in the theoretical literature of the method of brainstorming and its role in the process of learning and teaching, and the semi-experimental approach to detect the effect of the method of brainstorming and effectiveness in the development of students achievement in the English language grammar, compared to traditional methods of teaching, where the researcher used the experimental design of two groups: one experimental, the other control, applying the pre and post achievement test for the two groups.

\subsection{Study Design}

This study is described as a semi-experimental field; it is suitable for the objectives it seeks to achieve. It includes the following variables: independent variables; the method of brainstorming, the traditional method of teaching and the dependent variable; the semi-experimental design of the two equal groups was as follows:

- Experimental group: pre-test + application of brainstorming method in teaching + post-test.

- Control group: pre-test + application of the traditional method of teaching + post-test.

\subsection{Mechanisms of Implementation}

Male and female teachers were trained in the correct way to implement the steps of the lesson through the method of brainstorming, as well as the traditional method, to be fully committed by the male or female teacher to achieve objective and honest results, serve the purpose of the study, and it seemed clear by all participants, in cooperation with school administrations.

The researcher began applying the experiment over the second semester 2016-2017. The researcher has visited the schools repeatedly to follow up the implementation of the experiment, and check on the progress of the experiment according to the plan prepared in advance, and to provide any assistance or guidance to teachers and collaborators.

After the trial period, the post-test was performed and then the results were analyzed, as shown in the analysis of the study results later.

\section{The Results of the Study and Its Discussion}

One of the main objectives of the study is to find out the effect of the brainstorming method and the traditional method of teaching in the academic achievement in English grammar for sixth grade students in light of some basic demographic variables (gender of the students and the method of teaching). In order to test the study hypotheses, the researcher undertook a set of practical procedures to prove the acceptance of these two hypotheses or reject them on scientific and objective grounds. The results of these procedures and statistical treatments of the data obtained from the pretest and post-test, as follows:

Prior to the actual application of the study, the researcher conducted a preliminary test of the sample of the study: (experimental group), which will study English grammar using brainstorming strategy, and (control group) Which will study the same subjects using the normal (traditional) way, in order to determine the degree of parity of the two groups in the level of achievement in the English grammar. After obtaining the first results of the pre-test, the arithmetical averages and the standard deviations of the results were extracted as follows: 
Table 1. Means and standard deviations of the scores of the sample of the study sample in the pre-test in English grammar according to both: group variable, and gender of students variable

\begin{tabular}{lccc}
\hline \multirow{2}{*}{ Group } & \multirow{2}{*}{ Gender and number } & \multicolumn{2}{c}{ Results of pre-test } \\
\cline { 3 - 4 } & & Means & Standard deviations \\
\hline \multirow{3}{*}{ Experimental group } & Male (70) & 22.663 & 6.547 \\
& Female (50) & 22.209 & 5.067 \\
& Total & 22.436 & 5.867 \\
\multirow{2}{*}{ Control group } & Male (58) & 26.562 & 7.219 \\
& Female (56) & 25.515 & 6.664 \\
\multirow{2}{*}{ Gender } & Total & 26.038 & 6.941 \\
& Male (128) & 24.612 & 7.993 \\
\hline
\end{tabular}

The results of Table 1 show that the highest arithmetic mean scores in the English grammar test for the sixth grade level by group were in favor of the control group, with a value of $(26,038)$, while the experimental average of the experimental group (22.436), This result clearly indicates a difference of (3.602) scores between the average scores of the students in the pre achievement test.

To test the significance of this apparent difference between the arithmetic averages, the single-variance analysis test was used (One Way Anova), in order to determine the degree of equivalence of the sample members of the study, where the results are as follows:

Table 2. Results of the analysis of One Way ANOVA of variance of the scores of the sample of the study sample in the achievement test in English grammar depending on the group variable

\begin{tabular}{lccccc}
\hline Source of variance & Df & Sum of squares & Mean of squares & F value & Sig \\
\hline Between groups & 2 & 64.922 & 32.461 & & \\
Within groups & 115 & 1390.73 & 48.42 & & 0.067 \\
Total & 117 & & & & \\
\hline
\end{tabular}

It is evident from the previous results in Table 2 that the value of calculated (F) in degrees of freedom (2) is equal to $(03.618)$ and the statistical significance level is $(0.067)$, this value is not statistically significant: it came higher than $(\alpha=0.05)$ indicating that there were no statistically significant differences between the arithmetic mean of the pre-test achievement scores of the two groups in the English grammar test for sixth grade can be attributed to different groups, so this result is a reference to the existence of parity among the study sample members before actually applying the experiment.

Accordingly, and referring to Table 1, the results indicate that the mean of the achievement test mentioned in the gender variable was $(24,612)$ for males, with a standard deviation of $(7.993)$, while the average for females was $(23,862)$ and a standard deviation of $(7.080)$. These results indicate that there is a slight difference of $(0.750)$ between the average scores of both males and females in the pre- test.

To test the significance of this difference, T-test was used to compare the scores of the sample of the study in the pre achievement test according to the gender variable. The results were as follows:

Table 3. Test results (T) to compare the scores of individuals in the study sample in the achievement test in English grammar due to gender variable

\begin{tabular}{lccccc}
\hline Gender & Total number & Mean & Standard deviation & T value & Sig \\
\hline Male & 128 & 24.612 & 7.993 & & \\
Female & 106 & 23.862 & 7.080 & 1.466 & 0.025 \\
Total & 234 & 24.237 & & & \\
\hline
\end{tabular}

The results presented in Table 3 indicate that there are statistically significant differences between the scores of males and females in the pre achievement scores in the English grammar test for the sixth grade level in favor of males and appear to be small differences through the indicators in the results of the pre achievement test. The 
statistical significance of this test was (0.025), which is less than the statistical significance value $(\alpha=0.05)$ and can be attributed to different groups depending on the gender variable before actually applying the experiment.

\subsection{Results Related to Testing the Study Hypotheses}

\subsubsection{First: Results Related to the First Hypothesis of the Study}

The first hypothesis in this study is that: There are no statistically significant differences at the level of significance $(\alpha=0.05)$ between the mean scores of the two groups; experimental by the method of brainstorming in teaching, and control by traditional methods, due to the group variable and (teaching method) variable. In order to test this hypothesis in terms of acceptance or rejection, the statistical averages and standard deviations of the scores of the sample of the study sample were calculated in the following groups: (experimental and control) in the English grammar achievement post- test and the traditional method of teaching. The following table shows the results.

Table 4. Means and standard deviations of the results of the study sample in the post-achievement test according to the method of teaching variable

\begin{tabular}{lccc}
\hline \multirow{2}{*}{ Group } & \multirow{2}{*}{ Gender and number } & \multicolumn{2}{c}{ Results of the post test } \\
\cline { 3 - 4 } & & Mean & Standard deviation \\
\hline Experimental group & 120 & 27.000 & 6.729 \\
Control group & 114 & 23.567 & 6.754 \\
\hline
\end{tabular}

The results shown in the previous Table 4 show that there is a difference between the arithmetical averages of the experimental and control groups in the English grammar achievement test (3.433), where the mean of the experimental group scores reached (27.000). For the control group scores in the same test (23.567). To test the significance of this difference, the T-test was used, the results are as follows.

Table 5. Test results (T) to compare the scores of individuals of the two groups: experimental and control in the post achievement test in English grammar according to the variable (method of teaching)

\begin{tabular}{lccccc}
\hline Groups & Total number & Mean & Standard deviation & T value & Sig \\
\hline Experimental & 120 & 27.000 & 6.729 & \multirow{2}{*}{2.773} & \multirow{2}{*}{0.003} \\
Control & 114 & 23.567 & 6.754 & & \\
\hline
\end{tabular}

The results in Table 5 show that there are statistically significant differences between the two groups: experimental (following the method of brainstorming) and control; (following the usual teaching method) in the post-test, because the statistical significance level is $(0.003)$ of the statistical significance of the acceptance or rejection of hypotheses, and its value (0.05), where these differences came in favor of the experimental group that studied the English grammar by brainstorming method, and this indicates that this method, which is modern for students, contributed to raising their level of achievement in the acquisition and learning of grammar among sixth grade students through positive interaction by students, accompanying activities and the way in which educational learning situations are implemented in this area.

\subsubsection{Second: Results Related to the Second Hypothesis}

The second hypothesis in this study is that there are no statistically significant differences at the level of significance $(\alpha=0.05)$ between the mean scores of the experimental group students who studied using brainstorming method in the achievement of the English grammar due to the gender of the students (Male or female).

In order to test this hypothesis, the mean and the standard deviation of the experimental group scores in the post-test were calculated in the English grammar according to the gender of the students' variable (male and female). The results were as follows: 
Table 6. Means and standard deviations of experimental group members in the post achievement test due to gender variable

\begin{tabular}{lcccc}
\hline \multirow{2}{*}{ Group } & Gender & Number & \multicolumn{2}{c}{ Results of post-test } \\
\cline { 3 - 5 } Experimental group & Male & 70 & Means & Standard deviations \\
& Female & 50 & 16.140 & 4.193 \\
\hline
\end{tabular}

The results in Table 6, and by checking the comparative averages between the achievement level according to the gender of the experimental group (male and female) in the results of the post-test in the sixth grade English grammar, show a marked difference between the average of male and female scores (4.53) in order to test the significance of this apparent difference between the arithmetic mean of the sample, which is due to the gender difference of the students in the experimental group studied by the brainstorming method, the T-test was used for this purpose. The results are as follows.

Table 7. Test results (T) to compare the scores of experimental group members in a post achievement test in English grammar for the sixth grade according to gender variable

\begin{tabular}{lcccccc}
\hline \multirow{3}{*}{ Experimental group } & Gender & Total number & Mean & Standard deviation & T value & Sig \\
\cline { 2 - 7 } & Male & 70 & 16.140 & 4.193 & \multirow{2}{*}{2.078} & \multirow{2}{*}{0.002} \\
& Female & 50 & 20.670 & 4.583 & & \\
\hline
\end{tabular}

The previous results in Table 7 show statistically significant differences between males and females students of the experimental group in the post achievement test in English grammar for the sixth grade in favor of females, where the statistically significance reached (0.002), which is less than the statistical significance in these cases which is in this study: $(\alpha=0.05)$ This means rejecting the second zero hypothesis in this study.

\subsection{Discuss the Results of the Study}

Through the theoretical review of the literature of the study and its theoretical framework in talking about the method of brainstorming in teaching, and in the teaching of English grammar, the first objective of this study has been achieved through using the skills underlying the concept of brainstorming in teaching the subjects of English Grammar in the public schools at Wadi el-seer directorate of education, in order to raise the level of students' academic achievement during what has been reviewed and clarified in the theoretical framework in this study.

In light of the results obtained from the semi-experimental study in achieving the other objectives of the study through the application of experiment, the researcher relied on a major research question regarding the effect of using brainstorming method in teaching English grammar in the achievement of the sixth grade students in the public schools in Jordan for the required skills.

The results of the study showed that there are statistical significant differences indicating the superiority of the experimental group which was taught English grammar topics using the brainstorming method on the control group that studied the same subjects, at the same time using the traditional way. This can be attributed to the use of the brainstorming method in the teaching English grammar is based on a distinct teaching method, which raises students' abilities and enhances the positive interactive relationship between the teacher and the students, and between the students themselves, which reflected positively on their level of achievement in English grammar, and in the rest of the other subjects, in terms of complementarity of the various subjects in performance and achievement.

\section{References}

Abdelkader, M. (1997). The effect of using brainstorming in teaching Biology on the development of some biological concepts and scientific thinking among pupils in the first secondary grade. Educational Journal, 12(1), 1-31.

Abu Sneineh, O. (2008). The impact of using brainstorming method in the development of achievement and critical thinking in Geography among the students of the Faculty of Educational Sciences UNRWA Al-Najah University journal for Research (Humanities), 22(5).

Agha, M. (2009). The impact of the use of brainstorming strategy in the development of some mathematical thinking skills on both sides of the brain in the first grade students (Unpublished master thesis). Faculty of 
Education Islamic University, Gaza.

Hashempour, Z., Rostampour, M., \& Behjat, F. (2015). 'The effect of brainstorming as a pre-writing strategy on EFL advanced learner's writing ability. Journal of Applied Linguistics and Language Research, 2(1), 86-99.

Hassanein, H. (2002). Brainstorming Methods (Issue, 1). Amman, Dar Magdalawi.

Husari et al. (2000). General Teaching Methods. Al-Falah Library, Kuwait.

Jack, G., \& Kyado, J. (2017). Effectiveness of Brain-based Learning Strategy on Students' Academic Achievement, Attitude, Motivation and Knowledge Retention in Electrochemistry. Journal of Education, Society and Behavioral Science, 21(3), 1-13.

Qatami et al. (2008). Creative Thinking. Amman, Al-Quds Open University Publications.

Salamat, M., \& Kharabshah, Z. (2010). The effectiveness of brainstorming on the achievement of seventh grade students in geography and development of trends towards it. Educational Journal, 27, 357-383.

Shulah, G. (2009). The effect of brainstorming in teaching educational psychology on both curiosity and performance improvement on psychological tests with higher mental levels in Saudi Arabia. Journal of Education, 19(79), 228-256.

Tabtay, M. (2001) Developing Creative Thinking Capabilities. Dar Al Masirah Publishing, Distribution and Printing (1st ed.). Amman, Jordan

Wahib, M., \& Zidane, N. (2001). Thinking programs, types - strategies - methods. Dar Al-Elm for printing and publishing, Faculty of Education, Mosul University

Wisdom, J., Victoria, O., \& Emmanuel, F. (2016). Validity of Brainstorming Strategy on Students' Prior Knowledge and Academic Performance in Chemistry in Selected Secondary Schools in South-South Nigeria. American Scientific Research Journal for Engineering, Technology, and Sciences, 24(1), 113-130.

Ziadat, M., \& Adwan, Z. (2009). The Impact of Brainstorming on the Development of the decision-making skills of the ninth grade students in the field of National Education and Civil in Jordan. Journal of the Islamic University (Series of humanity studies), 17(2).

\section{Copyrights}

Copyright for this article is retained by the author(s), with first publication rights granted to the journal.

This is an open-access article distributed under the terms and conditions of the Creative Commons Attribution license (http://creativecommons.org/licenses/by/4.0/). 